\title{
The Research of Capacity Control Standard in Bridge Transition Section Subgrade Based on Measured Dynamic Stress
}

\author{
Xiushao Zhao ${ }^{1, \text { a }}$, Linli Mo ${ }^{2, b}$, Wei Liu ${ }^{1, \mathrm{c}}$ and Chenggang $\mathrm{Ai}^{1, \mathrm{~d}}$ \\ ${ }^{1}$ School of engineering and architecture, East China Jiaotong University, Nanchang, Jiangxi, \\ 330013, China \\ ${ }^{2}$ School of software, East China Jiaotong University, Nanchang, Jiangxi, 330013, China

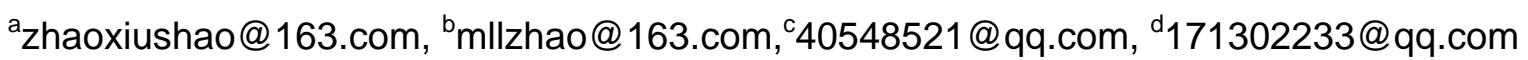

Keywords: Existing railway, Bridge transition section, Control standards, Bearing capacity

\begin{abstract}
The dynamic stress in existing bridge transition section of often bigger than ordinary roadbed due to its stiffness irregularity, so using the ordinary subgrade bearing standard as bridge transition section standard is inappropriate. Based on the measured dynamic stress in Xin-feng river bridge transition section, related standard for raising speed and Boussinesq's answer for stress in subgrade, Evd value and bearing standard in transition section subgrade are derived. Research shows that, Evd value control standard is not than $55 \mathrm{MPa}$ (fine-grained soil)and not less than $40 \mathrm{MPa}$ (coarse-grained soil). The bearing capacity control standard is not less than $210 \mathrm{kPa}$ for surface layer of subgrade and $180 \mathrm{kPa}$ for bottom layer of subgrade, which are $30 \mathrm{kPa}$ bigger than ordinary subgrade. The research provides a standard basis for reinforcement in existing railway bridge transition section.
\end{abstract}

\section{Introduction}

As a newly-built high-speed railway, The Railway Ministry of China has published the interim provision for new building passenger railway of $200-250 \mathrm{~km} / \mathrm{h}$, which provides strict rules for the dynamic deformation modulus( $E_{\mathrm{vd}}$ value), foundation coefficient $\left(K_{30}\right.$ Value) and subgrade compaction coefficient( $K$ value). But for the existing railway to speed up to $200 \mathrm{~km} / \mathrm{h}$, there is not based standard for bridge transition section subgrade, and current implementation of the standards developed in accordance with the ordinary subgrade of new railway, so it is necessary to discuss the control standards of bridge transition section subgrade in existing railway.

\section{The requirements of static and dynamic load on surface layer of subgrade}

Load calculated by theory static load and measured dynamic load superposition method, and the measured dynamic load is tested in Xin-feng River bridge transition section.

The static stress on the surface layer of subgrade produced by track and ballast. According to the book "subgrade engineering", track and ballast load calculated as static load. According to the standard, when the class I railway is heavy track, the thickness of ballast is $50 \mathrm{~cm}$, ballast severe is $20 \mathrm{kN} / \mathrm{m}^{3}$, and track weight is $0.6 \mathrm{kN} / \mathrm{m}$, sleeper length is $2.6 \mathrm{~m}$, the track and ballast load is $72.2 \mathrm{kN} / \mathrm{m}$. Therefore, the conversion static stress on the surface of subgrade is generated to $19.8 \mathrm{kPa}$, and then rounded up to $20 \mathrm{kPa}$.

The measured dynamic loading size and capacity requirements. The dynamic stress test results on subgrade at Xin-feng river bridge transition section on Ning-qi Existing railway shows in table 1 . The tested dynamic stress is very big due to serious ballast capsule. The maximum dynamic stress is $204 \mathrm{kPa}$ and average dynamic stress is $115.64 \mathrm{kPa}$.

Table.1 The dynamic stress test results at Xin-feng river bridge transition section

\begin{tabular}{|c|c|c|c|c|c|c|}
\hline Transition section name & \multicolumn{3}{|c|}{ Large mileage side } & \multicolumn{3}{c|}{ Small mileage side } \\
\hline Press box No. & 2151 & 2168 & 2118 & 2194 & 2187 & 2154 \\
\hline $\begin{array}{c}\text { The distance from the } \\
\text { abutment /m }\end{array}$ & 4.55 & 8.45 & 12.35 & 16.25 & 5.85 & 13.65 \\
\hline
\end{tabular}




\begin{tabular}{|c|c|c|c|c|c|c|}
\hline $\begin{array}{c}\text { The maximum dynamic } \\
\text { stress } / \mathrm{kPa}\end{array}$ & 85 & 85.13 & 115.41 & 52.32 & 151.48 & 204.55 \\
\hline
\end{tabular}

According to the dynamic stress test result at Xin-feng river bridge transition section, it can be seen track irregularities had huge impact on the subgrade surface and produced big dynamic stress, which is bigger than the dynamic stress calculated by theory, this is also the reason ballast capsule.

Due to the conversion ratio of dynamic to static stress, the subgrade's dynamic strength is about $60 \%$ of the static strength. According to the experimental results, the average dynamic stress at transition section is $115.6 \mathrm{kPa}$, corresponding to the demand for static strength of $192.7 \mathrm{kPa}$. Considering the static load generated by the track and ballast bed, the subgrade static strength requirement is $192.7+20=212.7 \mathrm{kPa}$, rounded up to $210 \mathrm{kPa}$.

The discussion of $\boldsymbol{E}_{\mathrm{vd}}$ value control standard for subgrade surface. In the railway subgrade design standard (TB10001-2005) ${ }^{[2]}$, foundation coefficient $\left(K_{30}\right)$ is the comprehensive index for subgrade strength testing and deformation. According to the studies of Datong-Qinhuangdao line, the corresponding relation between foundation coefficient ( $K_{30}$ value) and bearing capacity shows as follow ${ }^{[3]}$ :

$$
\left[\sigma_{0}\right]=0.24 K_{30}+0.015
$$

In the formula(1), the unit of $\left[\sigma_{0}\right]$ is $\mathrm{MPa}$ and the unit of $K_{30}$ is $\mathrm{MPa} / \mathrm{cm}$.

Foundation coefficient $\left(K_{30}\right)$ is the most direct method to detect subgrade on existing railway, but it is more difficult to test $K_{30}$ on the subgrade on existing railway, so it is rarely used and replaced by $E_{\mathrm{vd}}$. According to Wang C G's research, the conversion formula between $K_{30}$ and $E_{\mathrm{vd}}$ is $K_{30}=3.45 \times E_{\mathrm{vd}}+0.1^{[4]}$, then the following formula can be gotten:

$$
E_{v d}=\frac{\left(K_{30}+0.1\right)}{3.45}
$$

In the formula(2), unit of $E_{\mathrm{vd}}$ is $\mathrm{MPa}$ and the unit of $K_{30}$ is $\mathrm{MPa} / \mathrm{cm}$.

Formula (3) can be drawn from formula(1) and formula(2).

$$
E_{v d}=\frac{\frac{\left[\sigma_{0}\right]-0.015}{0.24} \times 100+0.1}{3.45}
$$

The conversion ratio of dynamic to static stress is 0.6 in literature ${ }^{[1]}$ and is 0.67 in literature ${ }^{[5]}$, then 0.6 ratio is taken considering safety. The maximum dynamic stress is $204 \mathrm{kPa}$ according to the test in Xin-feng river bridge transition section, so its equivalent static load is $340 \mathrm{kPa}$, and total static stress is $360 \mathrm{kPa}$, so $E_{\mathrm{vd}}$ requirements is $41.7 \mathrm{MPa}$ according to the formula(3).

Recommended control standard for $\boldsymbol{E}_{\mathbf{v d}}$ value. According to the interim provision for new building passenger railway of $200-250 \mathrm{~km} / \mathrm{h}$, the dynamic deformation modulus $\left(E_{\mathrm{vd}}\right)$ requirement for subgrade surface layer is $55 \mathrm{MPa}$, and $40 \mathrm{MPa}$ for subgrade bottom layer.

According to the calculation, the tested dynamic stress and related standard, transition section suffered dynamic stress is mainly controlled by the locomotive, and the $E_{\mathrm{vd}}$ requirement in standard is $55 \mathrm{MPa}$, which is bigger than the calculation's $41.7 \mathrm{MPa}$. Considering transition section subgrade's requirement is greater than ordinary subgrade, and most tested $E_{\mathrm{vd}}$ value on Ning-Qi existing railway can meet the $E_{\mathrm{vd}}$ demand, so the recommended standard is 55MPa. Exploration is easy to disturbed and can not get real Evd values when the surface of subgrade is coarse sand, the Evd value often lower than real Evd value. Considering coarse sand has the stability characteristics, $45 \mathrm{MPa}$ standard is recommended and the minimum value is not less than $41.7 \mathrm{MPa}$.

\section{The foundation bearing capacity requirement of each layer based on Boussinesq solution}

Under vehicle uniaxial loads, the simply dynamic stress distribution on the surface of subgrade shows as Fig.1. The dynamic stress distribution along transverse direction is a rectangular, which width is equal to the supporting layer. The dynamic stress distribution along longitudinal direction is triangular, and the maximum stress position is corresponding to the load position ${ }^{[6]}$. 


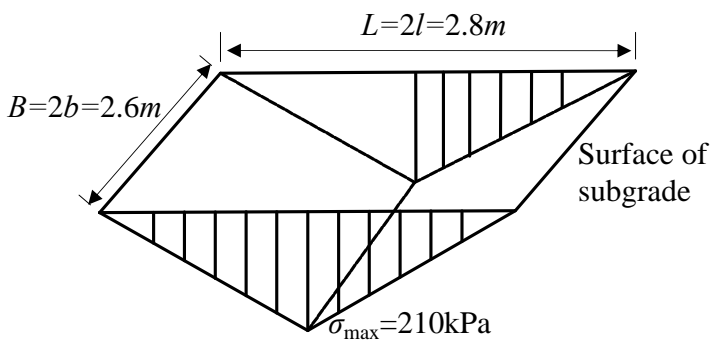

Fig.1 dynamic load distribution diagram

According to the Boussinesq's solution, the foundation bearing capacity requirements calculation of each layer is shown in table1, in which the maximum dynamic stress is taken as average tested stress $(115 \mathrm{kPa})$.

Table. 1 The stress calculation for each layer of subgrade

\begin{tabular}{|c|c|c|c|c|c|c|c|c|c|}
\hline Depth/m & 0 & 0.3 & 0.6 & 0.9 & 1.2 & 1.5 & 1.8 & 2.1 & 2.4 \\
\hline $\begin{array}{c}\text { Dynamic stress attenuation } \\
\text { coefficient }\end{array}$ & 1 & 0.911 & 0.726 & 0.715 & 0.487 & 0.395 & 0.322 & 0.266 & 0.218 \\
\hline Total static stress/kPa & 210 & 191.3 & 152.6 & 150.3 & 102.3 & 82.9 & 67.5 & 55.4 & 45.9 \\
\hline self weight stress of subgrade/kPa & 0 & 5.4 & 10.8 & 16.2 & 21.6 & 27 & 32.4 & 37.8 & 43.2 \\
\hline Total stress/kPa & 210 & 196.7 & 163.4 & 166.5 & 123.9 & 109.9 & 99.9 & 93.2 & 89.1 \\
\hline
\end{tabular}

According to table.1, the bearing capacity of subgrade surface layer(0-60) requirement should be not less than $210 \mathrm{kPa}$. When the depth is greater than $1.5 \mathrm{~m}$, the bearing capacity requirement is less than $100 \mathrm{kPa}$, and less then the requirement in railway standard(150kPa). But the low bearing capacity represents the compressibility increases, which can cause excessive settlement of transition section subgrade and is forbidden in the area. So the recommend bearing capacity requirement is not less than $166.5 \mathrm{kPa}$ (the max value of bottom layer of subgrade), rounded up to $170 \mathrm{kPa}$.

\section{Conclusions}

Due to the particularity of the transition section on existing railway, the transition section subject to dynamic stress is much larger than ordinary subgrade, so it takes improved soil as the surface layer of subgrade. Bridge transition section subgrade capacity requirement greater than ordinary subgrade, according to the railway standard and relational calculation some conclusions can be drawn as follows:

1)The $E_{\mathrm{vd}}$ control standard is $55 \mathrm{MPa}$ while the transition section filler is fine-grained soil or improved soil. While filler is coarse-grained soil, due to easy to disturbance and its self-stability, so the $E_{\mathrm{vd}}$ control standard is $40 \mathrm{MPa}$.

2) If using bearing capacity as control standard, the bearing capacity will not less than $210 \mathrm{kPa}$ for surface layer of subgrade in transition section, and not less than $170 \mathrm{kPa}$ for the bottom of subgrade.

\section{Acknowledgement}

This work is supported by National Natural Science Foundation of China (Grant No. 51208198), education subject of Jiangxi Province Department (No. GJJ11441) and ECJTU doctor startup funds(No. 01306022)

\section{References}

[1] Liu J L, Zeng Q L, Hou Y F. "Subgrade engeneering" [M]. China Railway Press publishing, China, 2006.8,p.62-68

[2] "Design provisional regulations for new construction railway at 200-250km/h" [S],China Railway Press publishing, China, 2005, in press.

[3] Xie R Q. The technological transformation in existing railway speeding up[J]. Subgrade 
engineering. 2003.5(110),p.1-5

[4] Wang C G. The relationship between dynamic deformation modulus(Evd) and foundation coefficient(K30)[J]. Subgrade engineering. 2004,21(2),p.4-6

[5] Han Z L. Research on the Counter measure of Railway Subgrade on Existing Railways[J]. China railway science. 2002, 23(2) ,p.53-58

[6] Huang J, Luo Q, Li J. Analysis on distribution of dynamic stresses of ballastless track subgrade surface under axle loading of vehicle[J]. Journal of the china railway society. 2010,32(2),p.60-66 